\title{
THE USE OF POLYMERIC REAGENTS IN ORGANIC SYNTHESIS
}

\author{
A. Patchornik and M. A. Kraus \\ Department of Organic Chemistry, The Weizmann Institute of Science, \\ Rehovot, Israel
}

\begin{abstract}
The main advantages offered by the use of polymeric carriers in organic synthesis are insolubilization and immobilization of the attached species and the possibility of creating special microenvironmental and steric effects.

Recent advances in the utilization of polymeric reagents in organic synthesis are discussed.

Polymeric transfer agents have been used for high yield acylations (e.g. peptide synthesis), for halogenation, for oxidation and reduction, in the Wittig reaction, in condensations and in other reactions. In this approach usually an excess of polymeric reagent is taken, so that a high yield of product is obtained in solution. In some of these reactions side products remain attached to the polymer, thus facilitating product purification.

Organic synthesis on polymeric carriers was originated by Merrifield in his peptide synthesis. Recent examples of synthesis by a similar approach are 'hooplane' synthesis, selective monoreactions of bifunctional compounds and oligosaccharide synthesis. In this reaction-type an excess of soluble reagent is usually employed.

Immobilization of reactive species on polymeric carriers was used in cyclizations, reactions of ester enolates with soluble reagents, mixed ester condensations, preparation of coordinatively unsaturated catalysts and enzyme subunit isolation. The success of these reactions is dependent upon chain length and concentration of the attached molecules and upon polymer crosslinking, reaction temperature and time.

Results obtained by the use of polymeric reagents are often difficult or impossible to duplicate in reactions under conventional homogeneous conditions.

Merits and limitations of the use of polymeric reagents in chemistry are discussed.
\end{abstract}

\section{INTRODUCTION}

Synthetic polymers have long been used almost exclusively for technological purposes. Chemical reactions of polymers (unlike the chemistry of their preparation) were rather little studied till the 1950s. During recent decades, however, a novel approach to polymers gradually developed. In this approach polymers are used as carriers for relatively low molecular weight reagents. The 'polymeric reagents' thus obtained are then treated with a soluble reagent in a proper solvent. Depending on the particular case the reaction product is either obtained in solution or remains attached to the polymer. In the latter case the product is cleaved off in a separate step. The purpose of 


\section{A. PATCHORNIK AND M. A. KRAUS}

such reactions is thus the modification of compounds reacting with the polymer, rather than of the polymer itself. This constitutes therefore a new concept from the points of view of both the organic chemist or biochemist on the one hand, and the polymer chemist on the other. The advantages of carrying out reactions with polymeric reagents are of three principal kinds.

(1) A soluble, low molecular weight compound, when attached to a crosslinked polymer, acquires the latter's property of complete insolubility in all common solvents. Moreover, if the polymer is of high porosity, the bound molecules will remain freely accessible to solvent and solute molecules and therefore not lose much of the reactivity they exhibit in solution. The insolubility of the polymeric reagent makes for its very facile separation from the other components of the reaction mixture. Hence a large excess of either soluble or polymeric reagent may be used, thereby increasing reaction rates and yields. The concept of facilitating separations by polymeric carriers is very broad. The polymer may be either organic or inorganic; the attachment may be done by chemical or physical means. Also soluble polymers may be used as carriers due to the ease of their separation from lowmolecular compounds by precipitation or membrane filtration.

(2) The polymeric carrier causes a restriction of the translational motion of the bound molecules to an extent which depends on the rigidity of the polymeric lattice. In a rigid polymer the attached molecules, at low concentrations, behave virtually as in a solution at infinite dilution. In this manner intermolecular reactions of the bound molecules or reactive species derived therefrom are inhibited and, according to the case, these molecules can be made either to react intramolecularly (e.g. cyclize) or to react selectively with an added, soluble reagent. At the other extreme of high concentrations of polymerattached species, a close mutual proximity is forced upon the bound molecules by the rigid polymeric backbone. This effect may be used to advantage for fast and selective reactions, in which two reactants are bound to a common polymer backbone.

(3) The polymer matrix constitutes a special environment for carrying out reactions. It will generally impose on molecules diffusing into it certain defined steric requirements (more stringent the higher the rigidity), determined by pore or channel structure, by substituents on the polymer backbone and by the distance between attached molecules and the polymer backbone. Also the polarity of the backbone is expected to have a pronounced effect on the reaction path of the bound molecules. These parameters may be varied at will when preparing the polymer, giving reaction environments tailor-made for specific purposes.

The literature on polymers as reagent-carriers has increased tremendously in recent years. Though obviously no attempt at an exhaustive review is being made in this article, mention will be made of the main types of processes in which polymeric reagents have been used to date. These reaction types are summarized in Table 1.

In reaction type 1 the polymer acts as a carrier for an enzyme or a nonbiological catalyst. Reactions utilizing such catalysts may be terminated at any desired moment by removing the polymer-catalyst. Polymer-attached enzymes and ion exchange resins were among the first polymeric reagents to be used in biochemistry and organic synthesis respectively. 
Table 1. Types of chemical uses of polymeric reagents*

\begin{tabular}{|c|c|}
\hline 1. $\mathbb{P} \longrightarrow \mathrm{A}+$ substrate $\rightarrow \mathbb{P}-\mathbf{A}+$ product & $\begin{array}{l}\text { polymers as catalyst carriers } \\
\text { (enzymes and non-biological } \\
\text { catalysts) }\end{array}$ \\
\hline 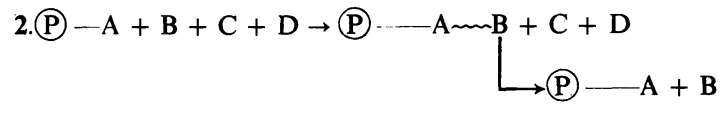 & $\begin{array}{l}\text { separations by specific } \\
\text { binding to polymers (affinity } \\
\text { chromatography, metal ion } \\
\text { separation) }\end{array}$ \\
\hline 3. $(\mathrm{P}-\mathrm{A}+\mathrm{B} \rightarrow \mathrm{P}+\mathrm{A}-\mathrm{B}$ & polymeric transfer agents \\
\hline $\begin{array}{l}\text { 4. } \underset{\rightarrow}{\rightarrow} \underset{\mathrm{P}}{ }+\mathrm{A}+\mathrm{A}-\mathrm{B}-\mathrm{C} \\
\rightarrow \mathrm{P}-\mathrm{P}-\mathrm{B} \stackrel{\mathrm{C}}{\rightarrow} \mathrm{P}-\mathrm{A}-\mathrm{B}-\mathrm{C} \rightarrow \\
\rightarrow\end{array}$ & $\begin{array}{l}\text { Merrifield-type and other } \\
\text { organic syntheses }\end{array}$ \\
\hline 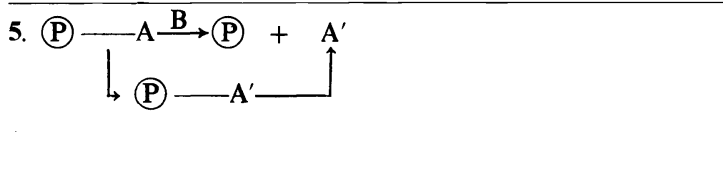 & $\begin{array}{l}\text { Intramolecular and other } \\
\text { 'matrix isolation' reactions } \\
\text { on polymeric carriers }\end{array}$ \\
\hline
\end{tabular}

(P) = Insoluble polymer

* Only main reaction types are presented. In the following review some reactions will be described which do not exactly fit any one of these types.

In type 2 a compound $B$ is separated from a complex mixture by reversible, specific binding to a polymer-attached reagent, A. After separation of the formed complex from the mixture, compound B is obtained in pure form by detaching it from the polymer. The popular separation method of biological compounds by affinity chromatography and separations of metal ions by polymer-attached specific ligands fit this scheme.

In type 3 the polymer acts as a reagent transferring a chemical group to (or to which a group is transferred from) a soluble reagent. The first polymers of this type were redox polymers, namely electron transferring reagents. An excess of polymer is usually used in this approach to ensure completeness of the reaction.

Sequence 4 represents the now famous Merrifield-type synthesis. Here the polymer acts as carrier in the stepwise construction of molecules made up of repeating, similar units, such as polypeptides, polynucleotides or polysaccharides. Excess soluble reagent is usually employed. After completion of the synthesis the product is cleaved off from the polymer. A number of other organic syntheses may be represented by a similar scheme.

In type 5 a rigid polymer helps in directing intramolecular reactions (e.g. cyclizations) of polymer-attached molecules, A, by preventing intermolecular reactions between them. The product, $A^{\prime}$, is obtained in solution either directly or after a separate cleavage step. This approach constitutes a general method for isolating reactive species from each other.

In the following discussion we shall confine ourselves to certain aspects of the use of polymeric reagents in organic synthesis, mainly ones in which we have been involved recently (reaction types 3,4 and 5 in Table 1). Excellent reviews exist on some other specific topics, such as immobilized enzymes ${ }^{1}$, 


\section{A. PATCHORNIK AND M. A. KRAUS}

ion exchange resins as catalysts ${ }^{2}$, redox polymers ${ }^{3}$, the Merrifield synthesis ${ }^{4}$ and affinity chromatography ${ }^{5}$. Also a few short reviews on the use of polymeric carriers in general organic synthesis have appeared recently ${ }^{6,7}$.

\section{POLYMERIC TRANSFER AGENTS}

\section{(A) Acylation by polymers}

In 1965 it was shown in our laboratory that polymers can be used as acylating agents ${ }^{8}$. By attaching benzoic or acetic acids to poly(4-hydroxy-3nitrosytrene) (I) active polymeric esters (II) were obtained, which could be used in acylations of amines ${ }^{9}$ (equation 1)

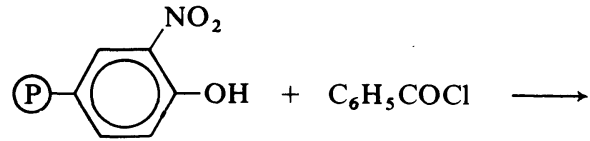

I

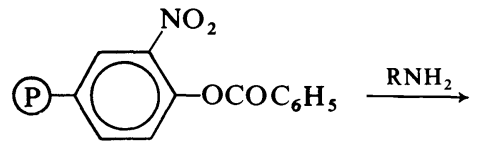

II

This approach gave rise to a general peptide synthesis ${ }^{9}$, outlined in equation 2.
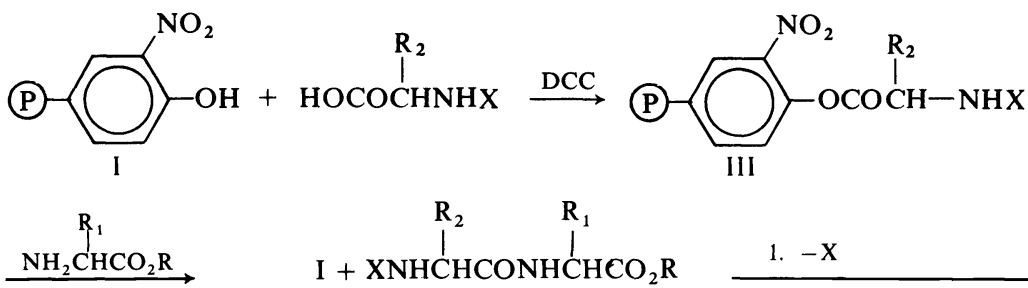<smiles>[Y19]NC([R])C(=O)NC([R])C([R])[R]</smiles>

IV

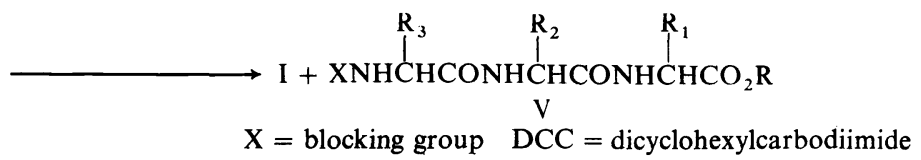

Amino acids bound to the nitrophenol polymer as active esters (III) are treated with a soluble amino acid of peptide having a free amino group. In contrast to the Merrifield synthesis the product of each step in the synthesis (IV), (V) is obtained in solution and may be purified if necessary. By employing excess polymeric reagent high yields of product are obtained. As an example of a multistep synthesis by this method the nonapeptide bradykinin was synthesized in an overall yield of 39 per cent ${ }^{10}$ (Scheme 1). The deprotected peptide showed full biological activity.

In spite of the considerable success achieved by the use of the above polymeric reagents they suffer from some disadvantages. Their powdery form causes difficulty in filtration and washing and prevents their use in a column for a continuous synthesis. Some of the polymeric preparations tend to 
THE USE OF POLYMERIC REAGENTS IN ORGANIC SYNTHESIS
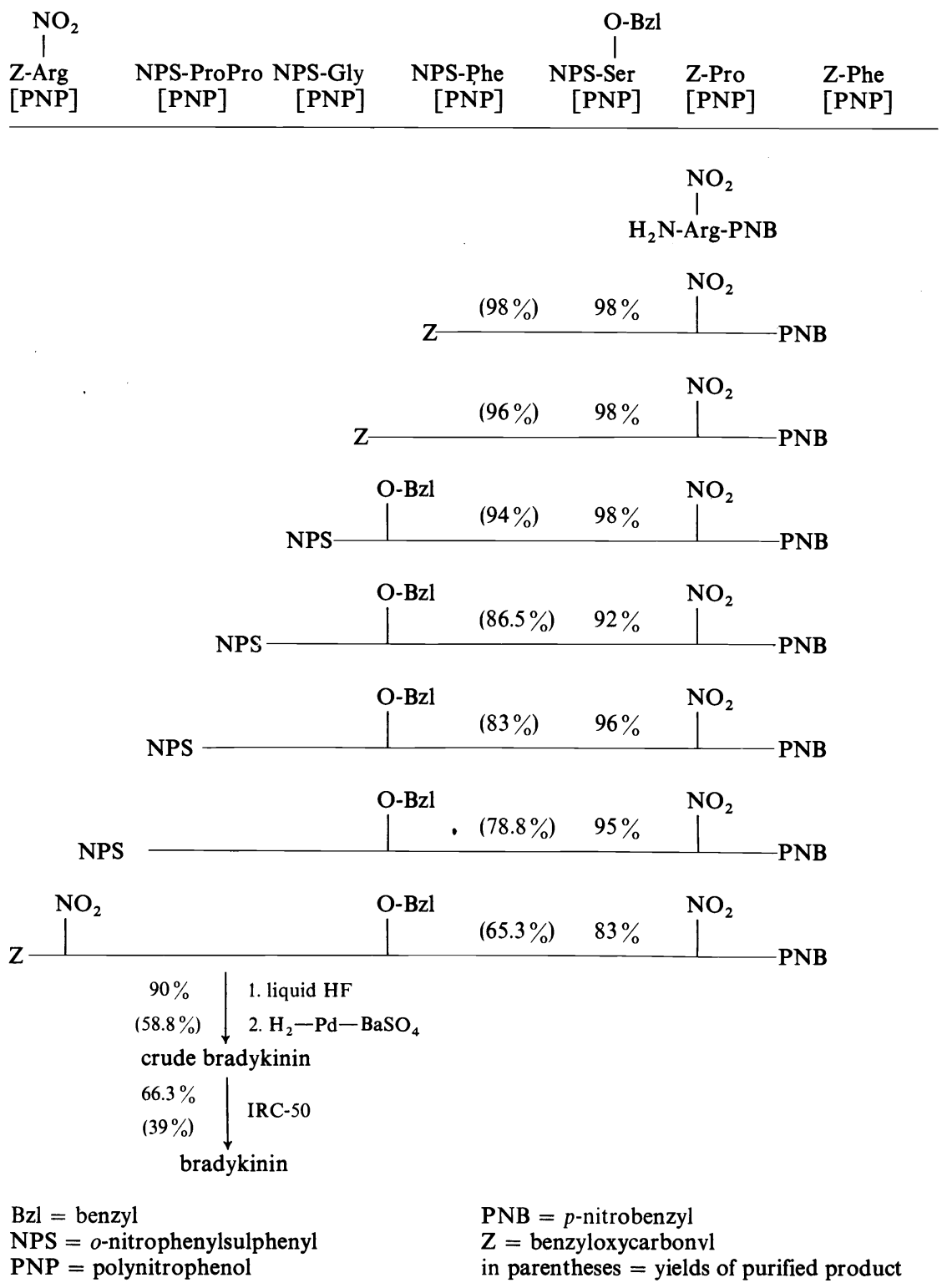

Scheme 1

disintegrate partially, liberating fine particles into solution. Also, these polymers swell only in a limited number of highly polar solvents. whereas a broader choice of solvents is desirable for a versatile peptide synthesis. Moreover a few reactions utilizing these polymers were found to be much slower than analogous reactions in solution. Therefore new polymers were sought which were to have both the chemical reactivity of the above polymers and 


\section{A. PATCHORNIK AND M. A. KRAUS}

the desired physical properties. Such polymers could be prepared by using preformed bead polymers as starting materials ${ }^{11}$, as described in Scheme 2.

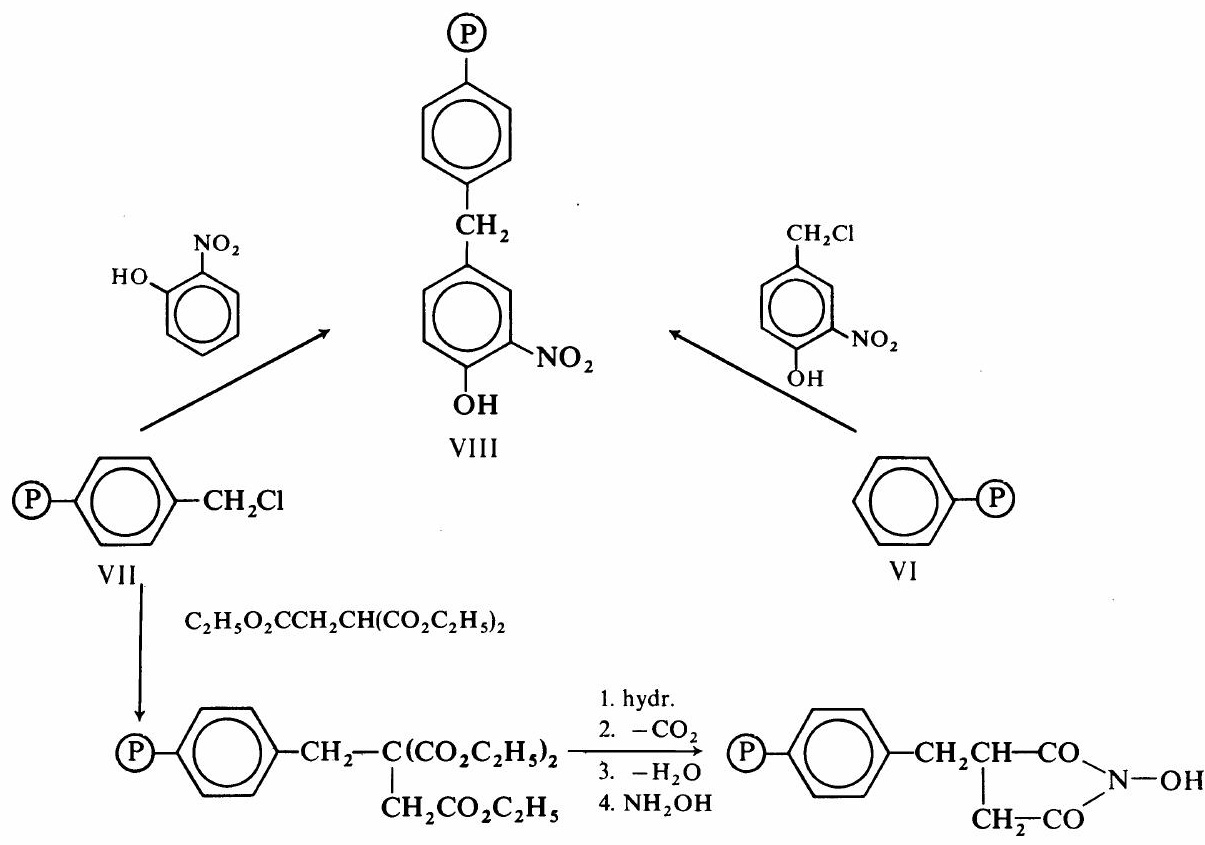

IX

Scheme 2

The most successful of these polymers proved to be the product (VIII) of Friedel-Crafts alkylation of polystyrene in bead form by 4-hydroxy-3nitrobenzyl chloride. The polymeric reagent retains the good mechanical properties of the starting polystyrene-two per cent divinylbenzene. It swells in a large number of solvents including dimethylformamide, methylene chloride and benzene. The polymer is easy to filter and wash. The binding of amino acids to the polymer (using DCC) was usually complete within three to five hours. Loadings of 1.0-1.5 mmol of amino acid per gram of polymer were usually attained with a polymer containing about $2.0 \mathrm{mmol}$ nitrophenol groups/g. For peptide synthesis a polymer-attached amino acid (in twofold excess) is treated with a soluble amino acid or peptide ester for five to twelve

Table 2. Peptide synthesis with 4-hydroxy-3-nitrobenzylated polystyrene

\begin{tabular}{|c|c|c|}
\hline Peptide & Yield, \% & No. of coupling steps \\
\hline $\begin{array}{l}\text { Z-Phe-Gly-OBzl } \\
\text { Z-Phe-Leu-OMe } \\
\left.\text { Boc }_{2} \text {-His-Pro-Phe-OBzl(NO }{ }_{2}\right) \\
\left.\mathrm{Z}_{2} \text {-Lys-Ala-Ala-OBzl(NO}{ }_{2}\right) \\
\text { Z-pGlu-His(DNP)-Trp-Ser(OBzl)-Try(OBzl)-Gly-Leu- } \\
\quad \text { Arg }\left(\mathrm{NO}_{2}\right) \text { Pro-GlyObzl }\end{array}$ & $\begin{array}{r}>99 \\
>99 \\
96 \\
99\end{array}$ & $\begin{array}{l}1 \\
1 \\
2 \\
2\end{array}$ \\
\hline
\end{tabular}


hours. Reaction rates are similar to those of analogous reactions in solution. They may be increased by warming. In most cases, evaporation of the organic solvent, obtained by filtering off the polymer, yields pure crystalline products. A few examples are summarized in Table 2.

That this method can be used for the preparation of considerable amounts of product was shown in a synthesis of the peptide Z-Asp(OBzl)Cys(Z)Gly $\mathrm{OBzl}^{12}$. In each of the two coupling steps about $20 \mathrm{~g}$ of polymeric reagent were used. Total volume was $80-100 \mathrm{ml}$. Yield of product was almost quantitative (about $10 \mathrm{~g}$ ).

Another nitrophenol polymer $(\mathrm{X})$ obtained by modification of bead polystyrene was reported in the literature ${ }^{12 a}$. It seems, however, that a $\mathrm{C}-\mathrm{C}$ bond,

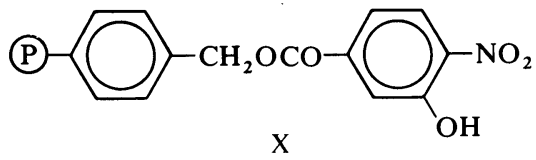

less prone to hydrolysis than an ester bond, is preferable. Also the reported product purity and yields obtained by this polymer are lower than with polymer VIII.

That the peptide synthesis by polymeric active esters does not preclude reactions with large peptides (because of possible steric effects) was shown by the reaction of insulin with carbobenzoxyalanyl co-polyethylene $N$-hydroxymaleimide. Alanination of insulin was quantitative ${ }^{13}$.

Recently we prepared a polymer bearing $N$-hydroxybenzotriazole moieties $(\mathrm{XI})^{14}$.

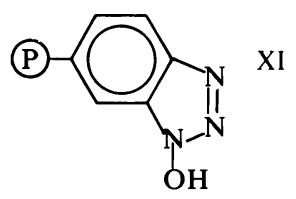

Syntheses with amino acids attached to this polymer are much faster than with other polymeric active esters. Even reactions with the polymeric derivatives of such bulky amino acids as valine, leucine and proline are finished within five to thirty minutes (6-24 hours are required with other polymers).

We have used polymeric esters in high yield syntheses of penicillins (XII) and cephalosporins (XIII).
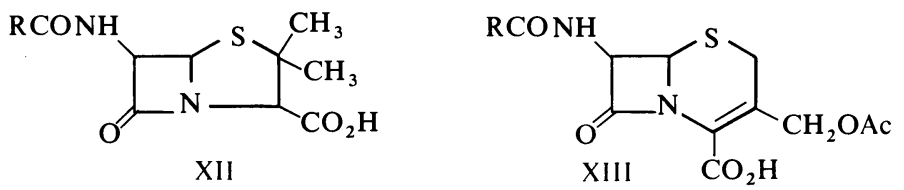

Special analytical methods were developed for the determination of polymeric active esters, mainly ones based on non-aqueous titrations.

At present preliminary experiments are under way in our laboratory toward automation of peptide synthesis by the active ester method.

Other groups of investigators have also used polymeric active esters in 


\section{A. PATCHORNIK AND M. A. KRAUS}

peptide synthesis. Wieland and Birr used $p, p^{\prime}$-dihydroxydiphenyl sulphone polymers ${ }^{15}$, and azophenol groups ionically bound to ion exchangers ${ }^{16}$. Blout and co-workers used $N$-hydroxymaleimide polymers ${ }^{17}$. Okawara and his group reported on $N$-hydroxysuccinimide and hydroxamic acid-containing polymers ${ }^{18}$. Marshall and Liener proposed the use of $p$-hydroxyphenyl sulphone polymers ${ }^{19}$. An insoluble nitroso aminopyrazole insoluble active ester was used by Guarneri et al. ${ }^{20}$.

Recently a polymeric mixed anhydride (XIV) was reported to be an effective acylating agent ${ }^{21}$ as described in equation 3.

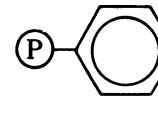

$\underset{\text { XIV }}{-\mathrm{COOCOC}_{6} \mathrm{H}_{5}}+\mathrm{C}_{6} \mathrm{H}_{5} \mathrm{NH}_{2}$
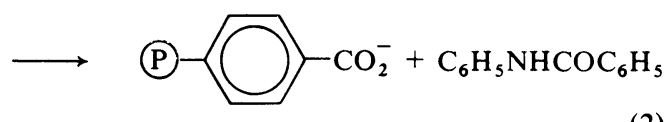

An interesting selectivity for attack at the carbonyl farther from the polymer was observed in this reaction. Steric hindrance to approach to the polymer backbone was suggested as an explanation of this effect.

Polymeric mixed sulphonic-acetic anhydrides were suggested recently as acetylating agents. However, reaction with alcohols larger than ethanol was slow $^{22}$.

\section{(B) Halogenations by polymers}

Polymeric halogenating agents offer advantages in handling, excess reagent removal and product isolation. The bromine complex of crosslinked polyvinylpyridine proved to be a mild, useful bromine donor (e.g. in additions to double bonds ${ }^{23}$. Poly( $p$-styryl iodide-chloride) (obtained by treating poly-p-iodostyrene with chlorine) was used successfully for the chlorination of cyclohexene to trans-dichlorocyclohexane ${ }^{24}$.

In reactions of polymeric reagents described till now the chemistry remained essentially unchanged compared to that of the analogous low-molecular weight reagent. Poly- $N$-bromo- and $-N$-chloromaleimide, however, showed unique reaction paths, different from those of the corresponding monomers ${ }^{25,26}$, as shown in Scheme 3.

The explanation of this difference lies in the polar nature of the polymeric backbone, providing a special microenvironment during halogenation, irrespective of the solvent used. This causes the dehydrobromination of the postulated primary reaction product (XX) to $\alpha$-methyl styrene. Then by consecutive bromination and dehydrobromination steps the formation of products (XVII), (XVIII) and (XIX) may easily be explained. Indeed when the solvent in reactions with monomeric $N$-bromosuccinimide (XVI) was changed from $\mathrm{CCl}_{4}$ to $\mathrm{CH}_{3} \mathrm{CN}$, product distribution was similar to that obtained with the polymer. Also when succinimide was added to the reaction mixture of toluene chlorination by monomeric $N$-chlorosuccinimide (XXIII) aromatic substitution increased from 16 to 95 per cent.

Recently both soluble and crosslinked poly( $p$-vinylbenzoyl chloride) were prepared and utilized in the conversion of carboxylic acids into their chlorides (50-90 per cent yields) ${ }^{27}$.

A somewhat unusual polymeric reagent in which the reactive groups are not attached by simple covalent bonds should be mentioned here. It was 


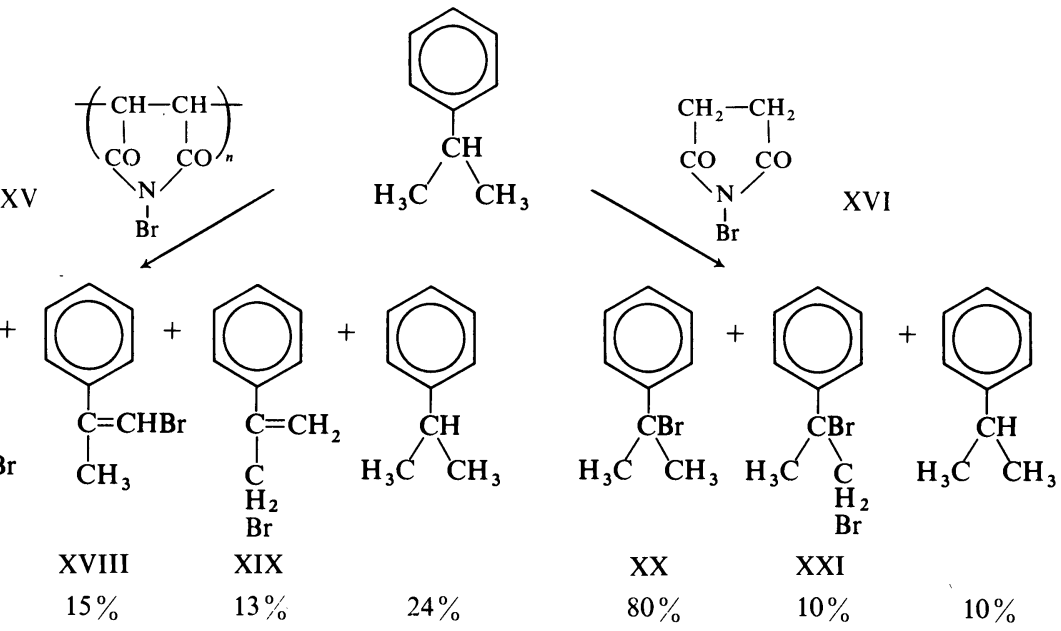

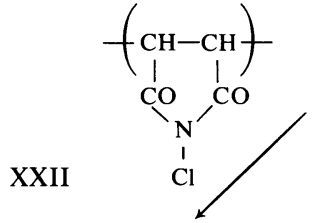

$100 \%$ aromatic substitition
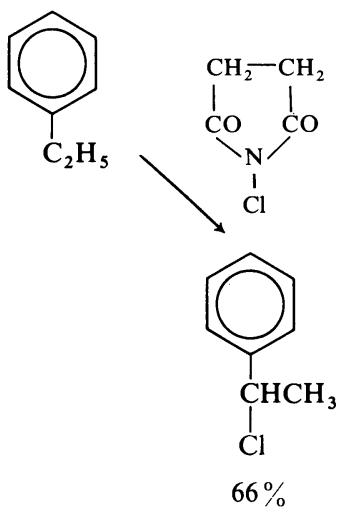

XXIII<smiles>ClCC(Cl)c1ccccc1</smiles><smiles>CCc1ccccc1</smiles>

$17 \%$

Scheme 3

shown recently that graphite insertion compounds may act as polymeric reagents. Thus the compound obtained by treating graphite with bromine was used in the bromination of 1,1'-binaphthyl and of 7-keto methyl cholanate ${ }^{28}$. Other reactions of graphite reagents are presently being studied by Drs Kagan and La Lancette.

\section{(C) New oxidizing and reducing polymers}

Redox polymers (usually quinone derivatives) were among the first polymeric reagents synthesized. Only a few recent additions will be described. Both Helfferich ${ }^{29}$ and Tagaki $^{30}$ prepared polymers containing peracid groups. Helfferich's polymer, prepared from a cation-exchange resin containing both carboxylic and sulphonic acid groups (by treatment with hydrogen peroxide), converts carboxylic acids to peracids and olefins to diols. Tagaki, using as starting material a resin containing only carboxy groups, obtained a polymer which converted olefins to epoxides. 


\section{A. PATCHORNIK AND M. A. KRAUS}

The use of poly(p-iodosodiacetate) as polymeric reagent was illustrated in the oxidation of aniline azobenzene ${ }^{24}$. Isoalloxazine-containing polymers were prepared and used in the oxidation of methyl mandelate ${ }^{31}$.

We have recently prepared a polymer useful for quantitative reductions of disulphide bonds in peptides and proteins ${ }^{32}$, as shown in equation 4.

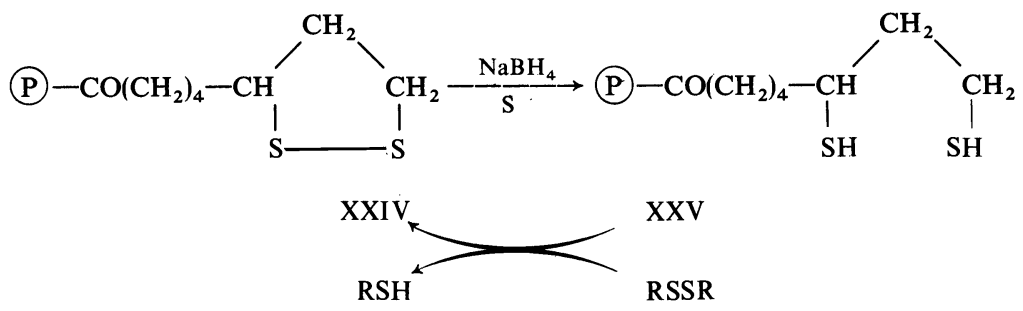

(P) = Cellulose, Sephadex, Polyacrylamide

Lipoyl residues are attached to polymers chosen so as to swell in aqueous solutions. The oxidized polymer (XXIV) may be easily and quantitatively regenerated by reaction with sodium borohydride. The polymer could be used for the quantitative reductions of glutathione and oxytocin and the activation of papain.

\section{(D) Polymeric Wittig reagents}

Three different groups reported on the preparation of alkylidene transferring polymers and their use in the Wittig reaction ${ }^{33-35}$ (equation 5).

(P)
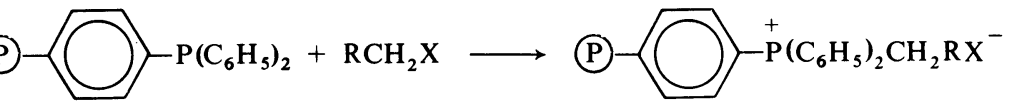

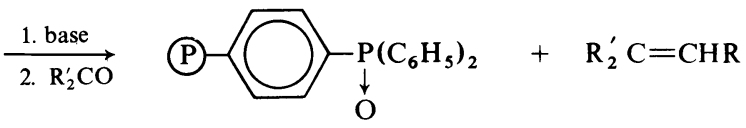

$$
\begin{aligned}
& \mathrm{X}=\text { halogen }
\end{aligned}
$$

The yields of olefins are usually similar to those of reactions with soluble phosphonium reagents. One advantage of the polymeric reagents is that triphenylphosphine oxide, which is sometimes difficult to remove, remains attached to the polymer. Another advantage concerns steric control of the reaction. The addition of lithium salts in the Wittig reaction is known to lead to the formation of trans olefins due to preferred complexation of the threo form of the betaine (XXVI).<smiles>[R]C([R])O[Z1]([R])([R])[PH2+]</smiles> 
Cis olefins are produced in the absence of lithium ions ${ }^{36}$. However, lithium bases are often used to generate the ylid. The use of polymeric phosphonium reagents made possible the complete elimination of lithium ions before addition of the carbonyl compound (by filtration of the polymer and washing ${ }^{37}$. Indeed cis olefins were obtained in high yield.

\section{(E) Polymeric condensing agents}

Hindered aryl sulphonyl chlorides are used as condensing agents in oligonucleotide synthesis as described in equation 6.

$$
\mathrm{ROPO}_{2}^{-} \mathrm{OX}+\mathrm{R}^{\prime} \mathrm{OH}+\mathrm{ArSO}_{2} \mathrm{Cl} \underset{2 \cdot \mathrm{H}_{2} \mathrm{O}}{\stackrel{1}{\mathrm{Py}}} \mathrm{ROPO}(\mathrm{OX}) \mathrm{OR}^{\prime}+\mathrm{ArSO}_{3} \mathrm{H}+\mathrm{HCl}
$$

$\mathrm{X}=$ base labile protecting group

Usual complications in such reactions are some sulphonation of $\mathrm{R}^{\prime} \mathrm{OH}$ and difficulties in complete removal of the sulphonic acid formed. When using a polymeric sulphonyl chloride (XXVII) prepared as shown in equation 7, no such problems were encountered ${ }^{38}$.
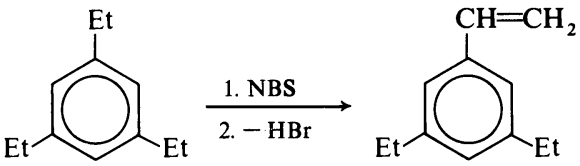

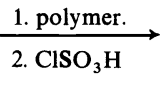

XXVII<smiles>CCc1cc(C(C)C)cc(S(=O)(=O)Cl)c1</smiles>

Reaction rates and yields were similar to those of reactions with soluble reagents; product purity was, however, much greater.

Recently a polymeric carbodiimide was prepared ${ }^{39}$ following equation 8 .
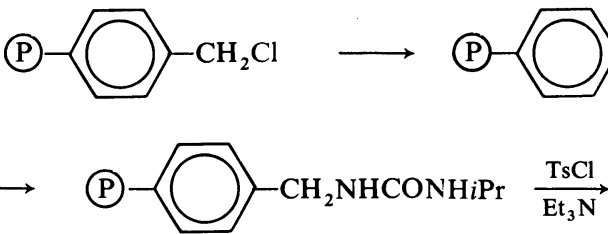

XXVIII

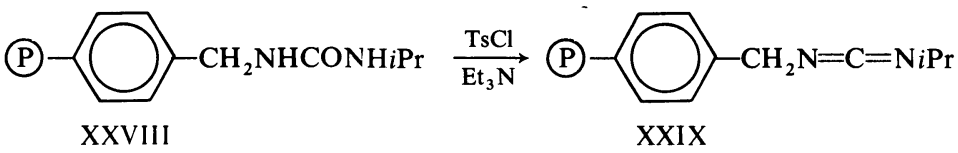

This reagent could be used successfully in the conversion of acids to anhydrides and of alcohols to aldehydes in the Moffat oxidation. The urea derivative formed (XXVIII) remains attached to the polymer and is easily separated from the reaction mixture. Thus a major difficulty in the use of carbodiimides is eliminated. Also, the urea derivative may be converted back to the diimide (XXIX). The regenerated reagent, however, is less active than the original one because of blockage of some diimide groups due to $N$-acyl urea formation.

Other polymeric diimides were used as condensing agents in peptide synthesis $^{40,41}$. Polymer-attached $N$-ethoxycarbonyl-2-ethoxy-1,2-dihydroquinoline (EEDQ) was prepared for the same purpose ${ }^{42}$.

Other polymeric reagents reported in the recent literature and which will 
A. PATCHORNIK AND M. A. KRAUS

not be discussed here are : a sulphonium ylid polymer (converting aldehydes to epoxides) ${ }^{43}$; metallating polymers [poly- $p$-lithium styrene and poly- $p$-(4lithiobutyl) styrene $]^{44,45}$; a polymeric Edman reagent used in stepwise peptide degradation $^{46} ;$ a polymeric Girard reagent ${ }^{47}$; crown ether containing polymers (alkali ion complexation) ${ }^{48}$; and pharmacologically active polymers $^{49}$.

\section{ORGANIC SYNTHESIS ON POLYMERIC CARRIERS}

In this section syntheses will be described in which the polymer serves as an insoluble support. After completion of the synthesis the product is split off from the polymer. This approach is in principle similar to the Merrifield synthesis (type 4, Table 1).

\section{(A) Hooplane synthesis}

Harrison and Harrison reported in 1967 on the synthesis of a compound (XXX) containing a new kind of topological bond, a 'hooplane'50. The insolubility of a polymeric carrier was utilized for increasing the yield of the desired product by many repetitions of the threading step in the synthesis, described in equation 9.
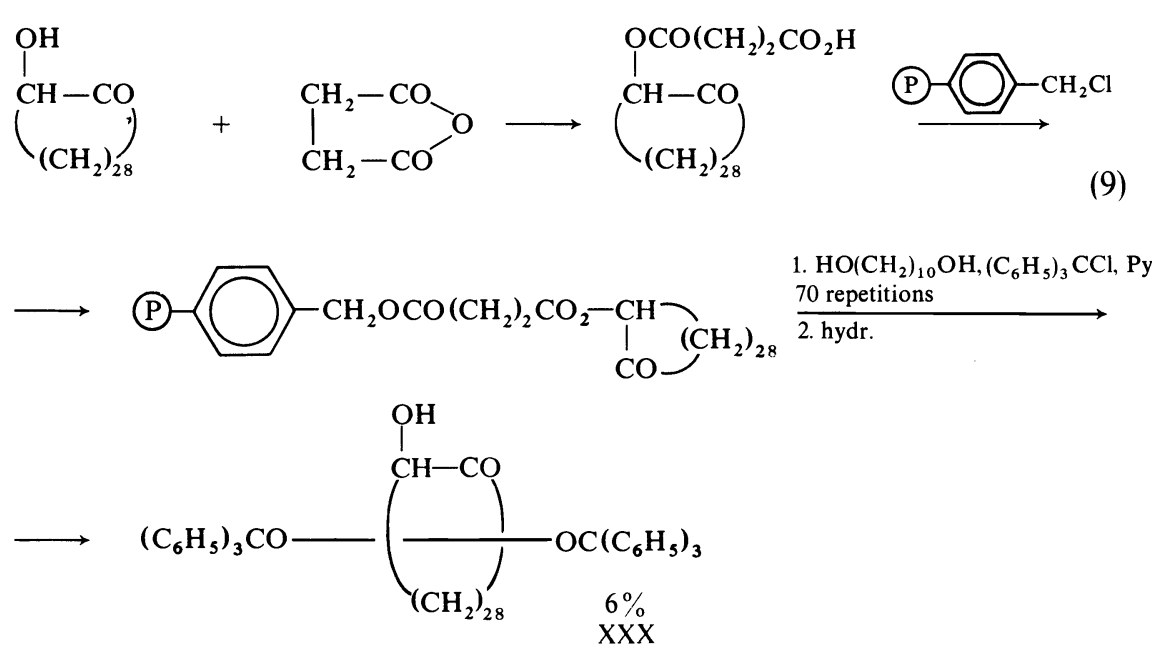

Unthreaded reactants could thus be easily removed. Such a sequence of reactions with soluble reactants only, would have been extremely difficult. A similar approach may be used for the synthesis of catenanes and other compounds formed in very low yields for statistical reasons.

\section{(B) Selective monoreactions of bifunctional compounds}

Leznoff $e t$ al. have used polymers for the selective blocking of one function in symmetrical bifunctional compounds ${ }^{51,52}$. As an example, the selective reaction of one hydroxyl in an $\alpha, \omega$-dialcohol is described in equation 10 . Bifunctional binding to the polymer is prevented by employing a large excess of soluble bifunctional reagent. Unreacted reagent is easily removed. [This is 
THE USE OF POLYMERIC REAGENTS IN ORGANIC SYNTHESIS

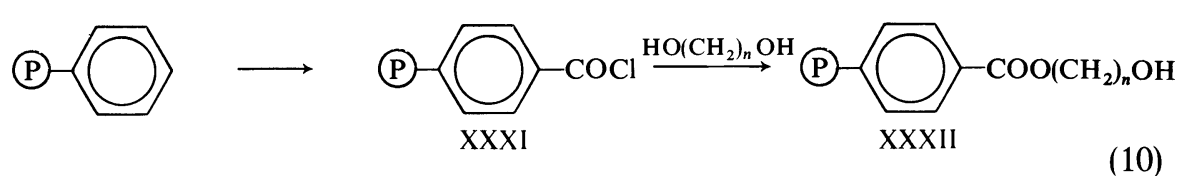

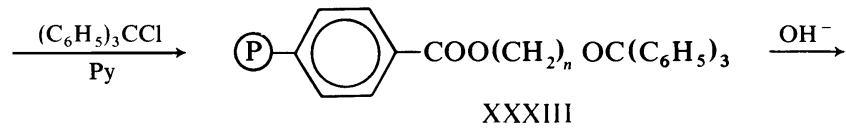

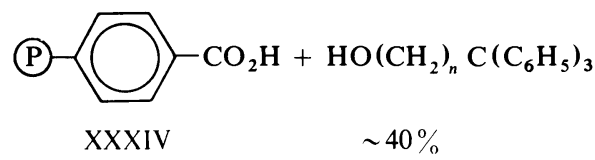

probably not a case in which functional groups on the polymer (XXXII) are isolated from each other. This conclusion is drawn by considering the relatively high concentrations of reactive polymeric groups in (XXXI) and the chain lengths of the molecules attached; vide infra]. After reaction of the unblocked functional group, the product is cleaved from the polymer. The functional group originally blocked is thus liberated. In attempts to reuse resin (XXXIV) it was found that yields decreased by 50 per cent per cycle. This was probably due to incomplete hydrolysis of (XXXIII).

By a similar route one aldehyde group in dialdehydes could be selectively reacted $^{52}$ as shown in Scheme 4.<smiles>OCC(O)COCc1ccc(C=C(Cl)CCl)cc1</smiles><smiles>O=Cc1cccc(C=O)c1</smiles>

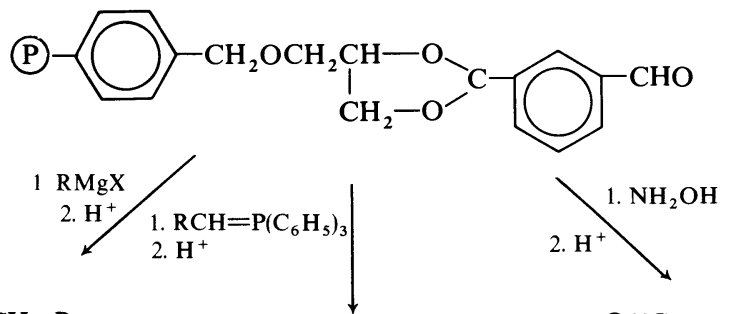

$\mathrm{OHC}$<smiles>[R]C(O)c1cccc(C)c1</smiles><smiles>O=Cc1cccc(C=NO)c1</smiles><smiles>[R]C=Cc1cccc(C=O)c1</smiles>

Scheme 4

In some of these reactions yields were quantitative and considerable absolute amounts of product could be obtained.

(C) Oligosaccharide synthesis on a photosensitive polymeric carrier We have recently reported on preliminary results of using a light-sensitive 


\section{A. PATCHORNIK AND M. A. KRAUS}

polymer as carrier in oligosaccharide synthesis ${ }^{53}$. A schematic description of the synthesis is presented in Scheme 5.

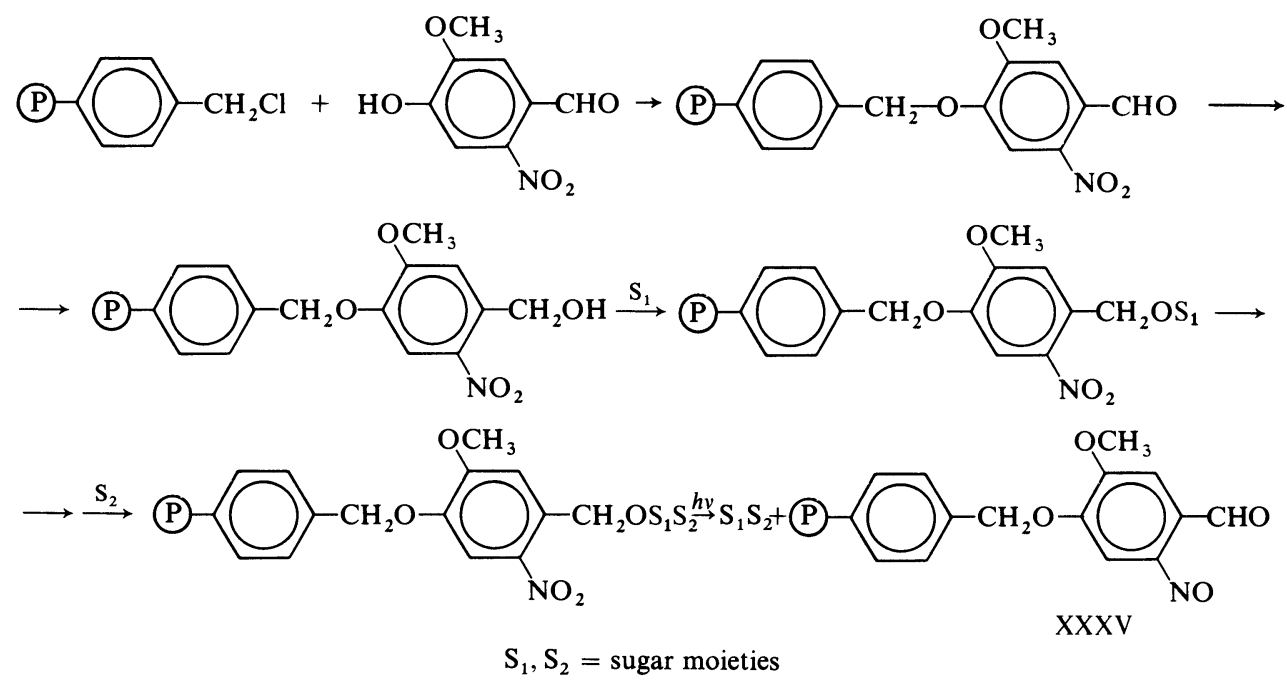

Scheme 5

The oligosaccharide is built on the polymer in a stepwise synthesis, by a route analogous to that used by Schuerch et al. ${ }^{54}$. The product is released from the polymer under mild conditions by irradiation. In the cleavage step the polymer is converted to the corresponding nitroso aldehyde (XXXV).

\section{POLYMERS AS IMMOBILIZING MEDIA}

The matrix isolation method (the irradiation of molecules trapped in glasses at low temperatures) has long been known as a route to trapping of short-lived reactive species ${ }^{55}$. The use of crosslinked polymers for isolating organic reactive species from each other is a logical extension of this approach. However, there are differences. First, if the polymer is rigid enough, ambient temperatures may be employed. Secondly, the porosity of the polymeric matrix makes the polymer-attached moieties accessible to soluble reagents. Reactive species may, therefore, be generated not only by photochemical but by chemical means also. The reactive species may then be reacted chemically in directed, selective reactions.

\section{(A) Cyclizations on polymeric carriers}

The most obvious application of this method is the preparation of cyclic compounds, and indeed syntheses of cyclic peptides were the first reactions in which this approach was utilized.

In many cyclization reactions a high dilution technique is employed in order to prevent inter- and promote intramolecular reaction. The use of a rigid polymer as carrier for the molecules to be cyclized may replace this technique. Concentrations allowable on the polymer are expected to be considerably higher than those in solution. 
THE USE OF POLYMERIC REAGENTS IN ORGANIC SYNTHESIS

The synthesis of cyclic peptides with polymeric active esters ${ }^{56}$ is described in equation 11.
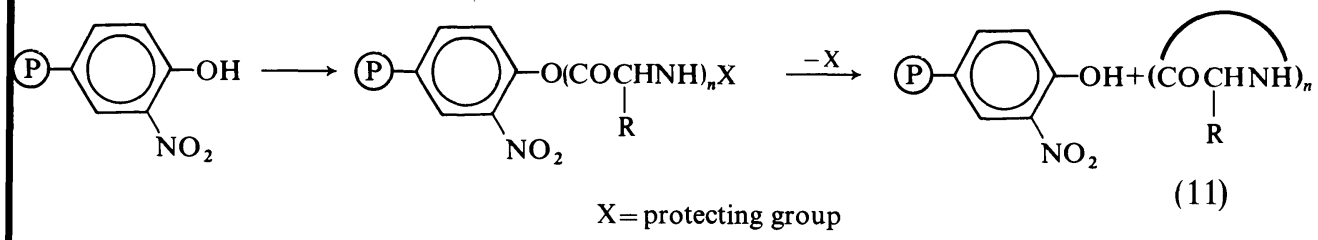

Cyclo (Gly-Gly) and cyclo (tetra-L-Ala) were obtained in 75 per cent and 50-65 per cent yield respectively. Other investigators used a similar approach. The glycine analogue of gramicidins (a cyclic decapeptide) was prepared by stepwise synthesis of the corresponding linear peptide on a polymeric carrier followed by cyclization ${ }^{57}$. The yield of product, based on the amount of peptide originally attached to the polymer was 20 per cent.

In another interesting approach Marshall et al. combined the Merrifield and active ester methods ${ }^{58}$ as shown in equation 12.
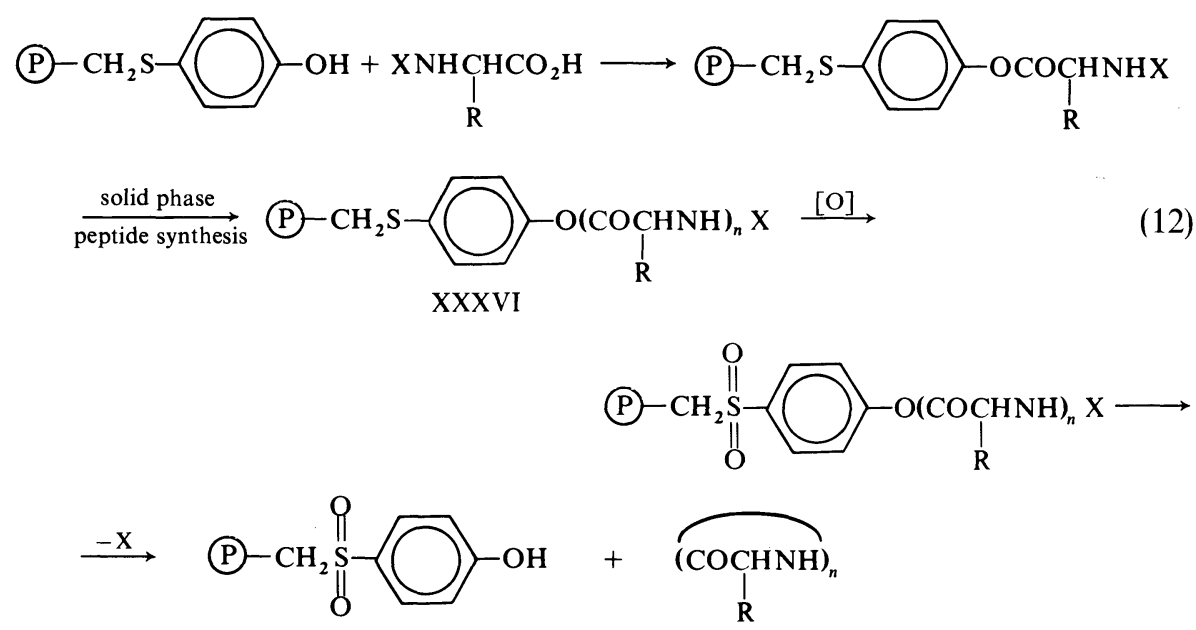

Prior to cyclization the polymeric ester is activated by oxidation of the sulphide (XXXVI) to the corresponding sulphone. Cyclic di-, tetra- and hexapeptides were prepared by this method in reasonable yield.

The preparation of cyclic $\beta$-ketoesters was described by Crowley and Rapoport ${ }^{59}$. Specifically substituted and radioactively labelled compounds could be obtained as shown in equation 13 .

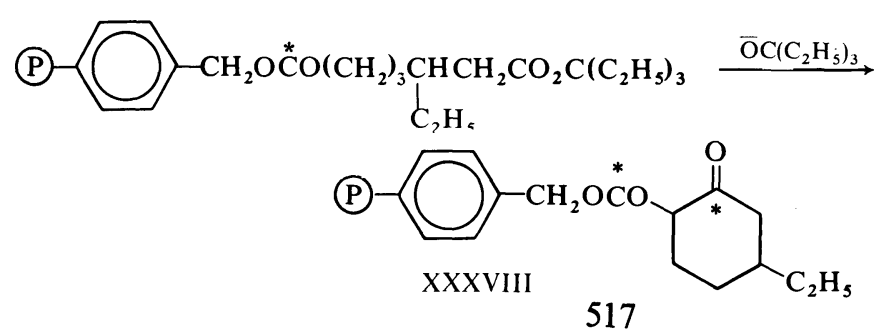<smiles>CCCCCC(=O)C(CC)C(=O)OCCC</smiles>
XXXVII 


\section{A. PATCHORNIK AND M. A. KRAUS}

The separation of the products (XXXVII) and (XXXVIII) was easy since one (XXXVIII) remained attached to the polymer. Such a separation would have been extremely difficult under conventional conditions. The product released into solution was labelled specifically at carbon 1. (It was later reported that in the product which remained attached to the carrier scrambling of the labelling occurred. The implication of this fact as to the rigidity of the polymer will be discussed in the following.)

We have been studying the Dieckmann reaction and a number of other organic cyclizations on polymeric carriers ${ }^{60}$. Some of these reactions are described in equations $14-17$.
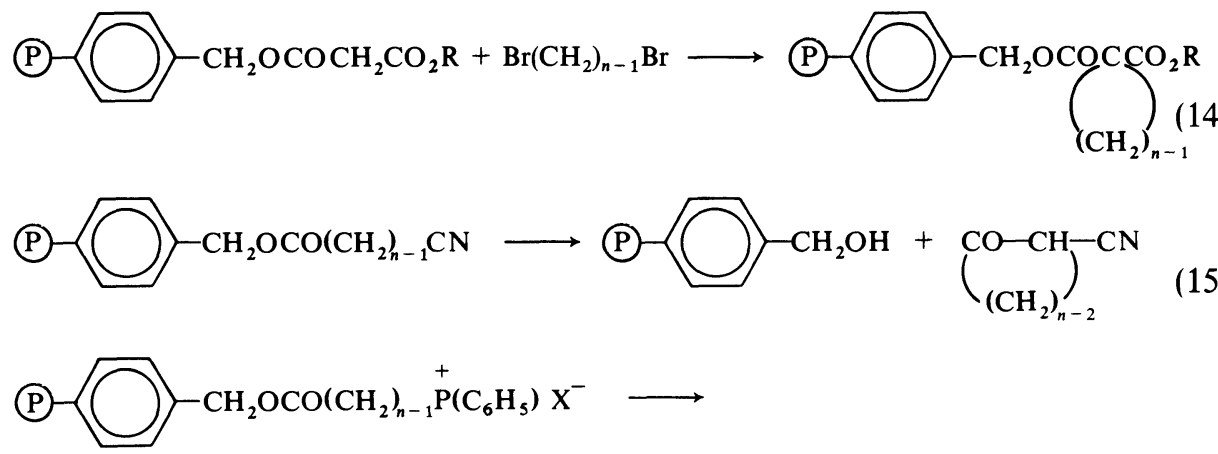

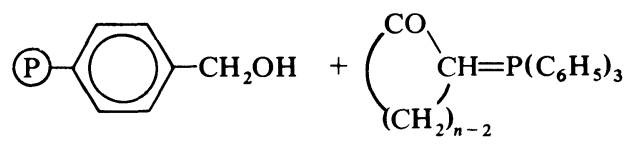<smiles>CC1(COCc2ccc([18O])cc2)COC(CCC#N)(CCC#N)CO1</smiles>

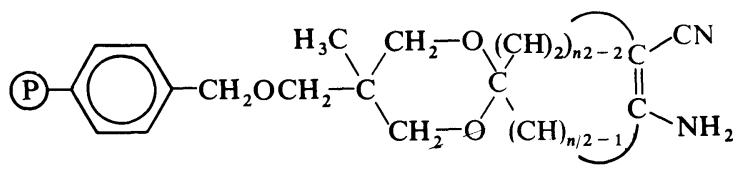

Usually in these reactions, good yields of pure products were obtained only in syntheses of 5- and 6-membered rings. Attempts to prepare medium and large rings resulted in very low yields. Extensive intrapolymeric intermolecular reaction was detected in the latter reactions.

In another kind of reaction, however, the polymeric carriers behaved as effective isolating matrices. This difference is due to a difference in reaction conditions, as will be apparent from the following. Polymer attached ester enolates (XL), isolated from each other, could be formed by treating polymeresters (XXXIX) with the proper base. The enolate ions could be treated with various electrophylic reagents as described in Scheme 6. In every case a single product was obtained and the common competing reactions of self condensation and double substitution were thus inhibited ${ }^{60-62}$. 
THE USE OF POLYMERIC REAGENTS IN ORGANIC SYNTHESIS

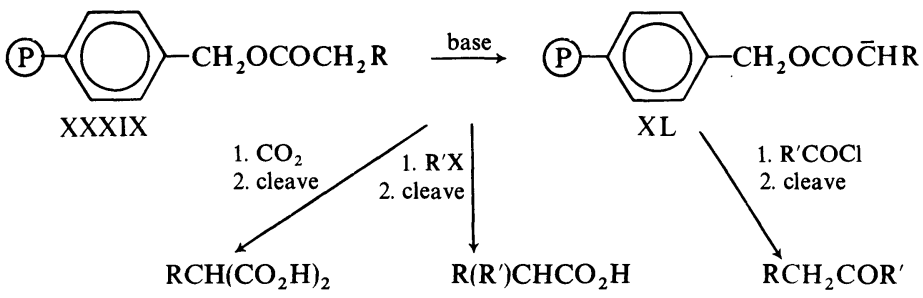

Scheme 6

Similar reactions in solution, conducted under identical conditions, resulted in extremely complex mixtures and yields of the desired products were lower.

The success of these reactions was found to be strongly dependent on the reaction conditions employed. In the reactions described the polymer used was polystyrene- $2 \%$ divinyl benzene. Concentration was $0.1-0.2 \mathrm{mmol} / \mathrm{g}$, temperature was $0^{\circ} \mathrm{C}$ to ambient and reaction time, about five minutes. Increasing self condensation was detected upon increasing any one of these parameters. Other carriers used in these reactions were 'popcorn' and macroporous polystyrenes. With the popcorn polymer higher concentrations $(0.3-$ $0.4 \mathrm{mmol} / \mathrm{g}$ ) could be used and better yields were attained ${ }^{63}$.

A polymeric immobilization effect was detected also at the other extreme of high concentrations of attached species ${ }^{64}$. A mixed ester condensation of two polymer-attached esters was carried out as described in equation 18. Two

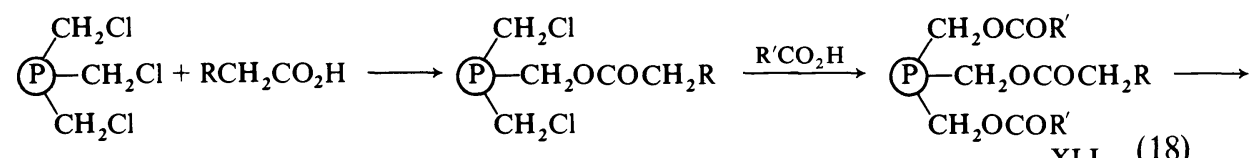

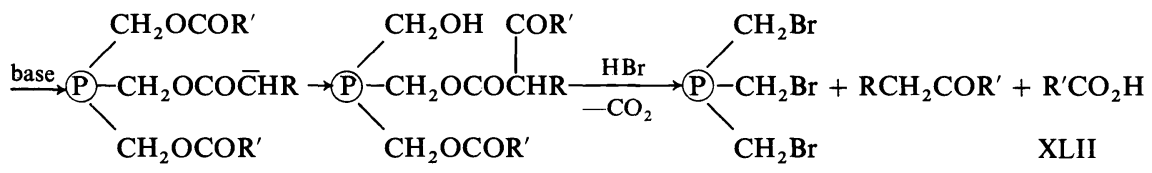

acids were attached to a common polymeric carrier - an aliphatic acid at low concentration ('infinite dilution') and an aromatic acid at high concentration. Upon treatment of the polymer (XLI) with base (e.g. trityllithium, $5 \mathrm{~min}$ ) and cleavage, a single ketone (XLII) was obtained, accompanied only by unreacted aromatic acid. A strong dependence of the yield of ketone (XLII) on the concentration ratio of the two esters in the polymer was found. When ratios were high enough $(>10)$ yields were nearly quantitative. These results could not be duplicated in reactions in solution, performed under identical conditions. In the latter reactions complex mixtures were obtained, and self condensation of the aliphatic ester could not be prevented. Thus the polymer acts to separate aliphatic ester moieties from each other and to bring about a close proximity of aliphatic to aromatic ester groups. The concentration dependence of the yields implies immobilization for the duration of the reaction (a large 


\section{A. PATCHORNIK AND M. A. KRAUS}

excess of aromatic over aliphatic ester was used in all experiments). Apparently when concentration ratios are not high enough, aliphatic ester groups are isolated both from each other and from aromatic ester moieties.

A number of other reports on the immobilization of reactive species on polymers have appeared in the recent literature. The attachment of homogeneous catalysts to polymers has received great attention recently. A few groups of investigators reported on attempts to prepare coordinatively unsaturated catalysts by utilizing the polymeric immobilization method. Grubbs et al. apparently succeeded in obtaining 'free' titanocene ${ }^{65}$ as described in equation 19.

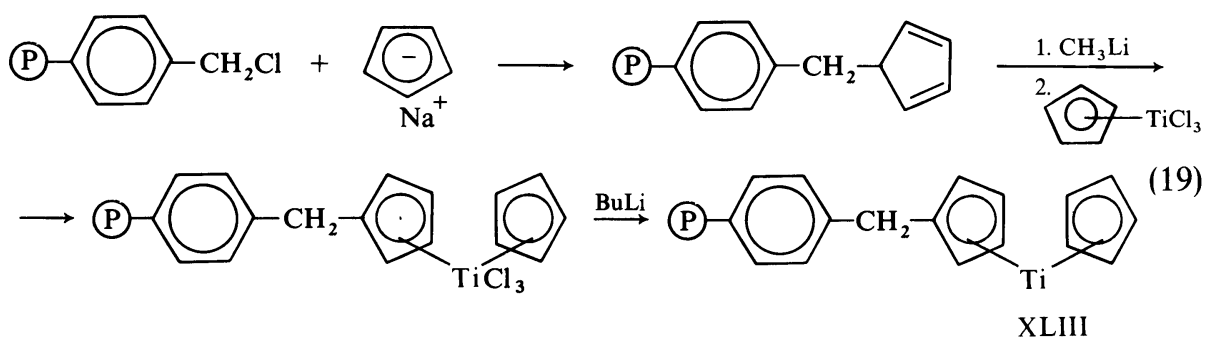

Polymer (XLIII) was highly reactive in catalysing reductions of olefins and acetylenes. A similar reaction sequence in solution yielded a product much less active. Coordinatively unsaturated rhodium catalysts could be obtained by a similar route. The polymeric carrier used in these experiments was 20 per cent crosslinked macroporous polystyrene, and the loading was relatively high $(0.8 \mathrm{mmol} / \mathrm{g})$. Collman et al. reported on the preparation by a similar method of extremely small metal atom clusters whose coalescence to large aggregates was inhibited by the polymer ${ }^{66}$ (equation 20 ).

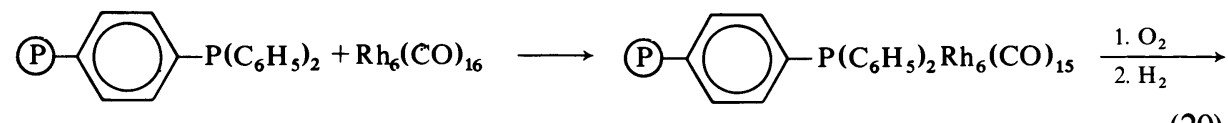

The polymer-embedded metal cluster (XLIV) catalysed the hydrogenation of arenes at $25^{\circ}$ and $1 \mathrm{~atm}$ of hydrogen, and could be reconverted to $\mathrm{Rh}_{6}(\mathrm{CO})_{16}$ by treatment with carbon monoxide.

The same approach has been used recently in an elegant method to obtain isolated enzyme subunits. Fructose-1,6-diphosphate aldolase, consisting of four identical subunits, may be dissociated with urea. In solution, upon removal of the urea, the subunits reassociate. By attaching aldolase at low concentrations to a polymer (Sepharose 4B), treating with urea, and washing, isolated subunits were obtained ${ }^{67}$. It could be shown that the subunits possess enzymatic activity. The whole enzyme could be reconstituted by 
THE USE OF POLYMERIC REAGENTS IN ORGANIC SYNTHESIS

adding soluble subunits to the polymer-attached subunits as shown in Scheme 7.
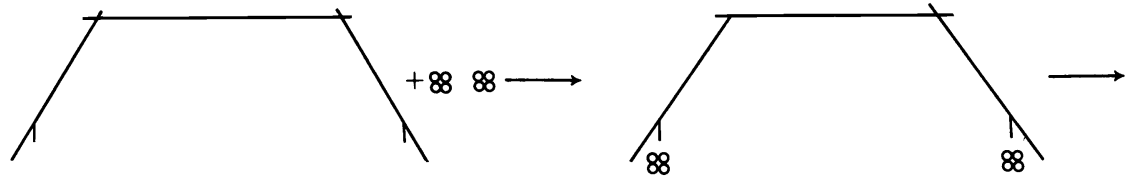

urea
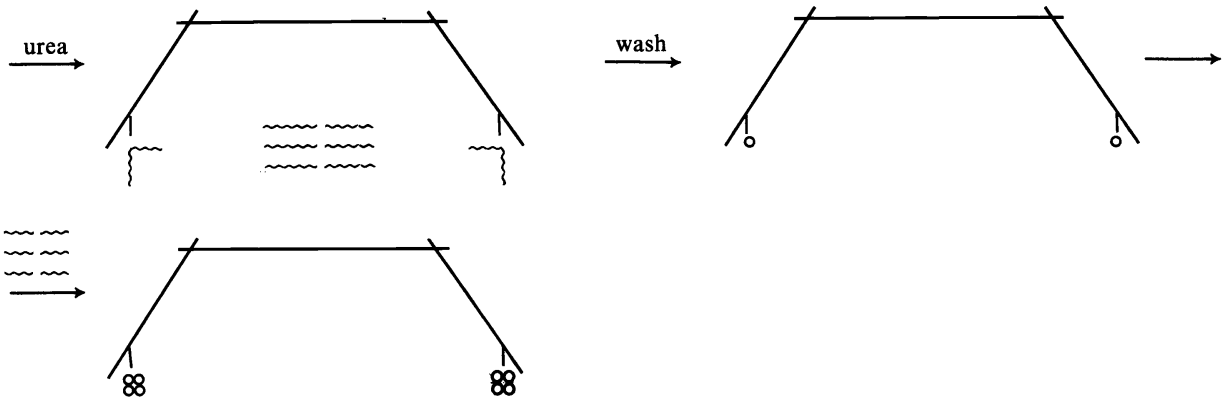

Scheme 7

In a similar study avidin subunits were isolated from each other on Sepharose ${ }^{68}$. In this case it was found that some subunit association occurs even on the polymer. The extent of this association could be increased by heating and decreased by crosslinking of the polymer.

A few instances in which the polymer did not act as an immobilizing medium were also reported. Extensive label scrambling of the polymerattached product (XXXVIII) of the Dieckmann cyclization (vide supra) was interpreted by Rapoport et al. to be a result of rapid intrapolymeric transesterification ${ }^{69}$. Other indications of polymer mobility cited by these authors were intermolecular reactions in cyclizations of polymer-attached chains and intrapolymeric anhydride formation, shown in equations $21-22$.
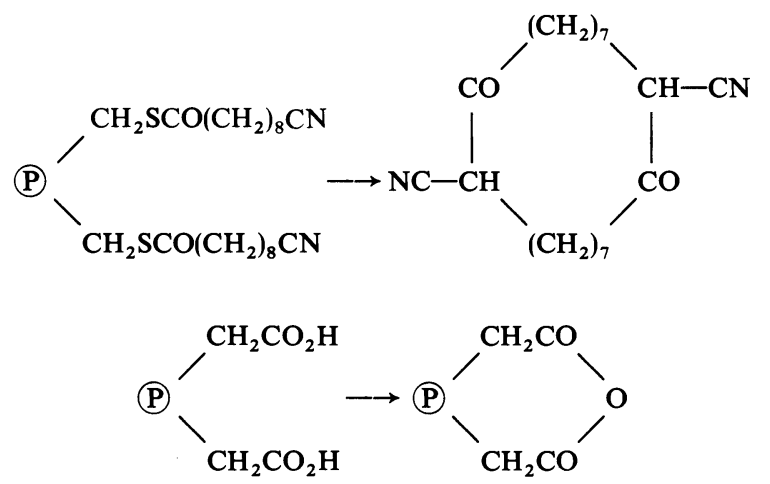

Collman et al. reported on unsuccessful attempts to obtain coordinatively unsaturated polymer-bound $\mathrm{Rh}$ catalysts ${ }^{66}$ and iron porphyrins ${ }^{70}$. Multi- 


\section{A. PATCHORNIK AND M. A. KRAUS}

functional instead of monofunctional binding to the polymer apparently occurred in these experiments.

Zahn et al. carried out high yield intrapolymeric oxidations of polymerbound cysteine residues to the corresponding cystine moieties ${ }^{71}$.

In order to reconcile these apparently conflicting results it is suggested that the experimental conditions be considered carefully when attempting to correlate chemical experimental data with the rigidity of polymers. Certain conditions may lead to 'intrapolymeric' interactions even in ideally rigid polymers, e.g. high concentration of the attached species, a large distance between the functional groups of the bound molecules and the polymer backbone or an inhomogeneous distribution within the polymer. In polymers which are somewhat mobile, one should expect also a dependence of the extent of intrapolymeric reaction on the temperature, reaction time, solvent and charge formation on the polymer. Thus in the most successful immobilization experiments described above, either highly crosslinked polymers were used (e.g. titanocene synthesis, enzyme subunit separation) or reactions of short duration at ambient temperature were carried out (e.g. ester acylation). Increased intrapolymeric interaction was detected when attached molecules had long chains (e.g. cyclizations) or when high temperatures (e.g. Dieckman cyclization) or long reaction times (e.g. cysteine oxidation) were employed. We could demonstrate the effect of reaction time by carrying out two identical polymer-ester acylations differing only in the time interval between enolate formation and its reaction (5 versus $20 \mathrm{~min}$ ). In the longer experiment product yield was lower ( 12 per cent versus 25 per cent) and self condensation higher ( 5 per cent versus 1 per cent). Effects of both solvent and peptide chain length on intrapolymeric sulphhydryl oxidations were noted by Zahn. It is concluded that the most common polymeric carrier-polystyrene- $2 \%$ divinyl benzene-when solvent swelled possesses a certain mobility. This mobility is much less than that of small molecules in solution as shown in the reactions of polymer esters described above. (That the dry polymer is rigid at ambient temperature is shown by the fact that hydroxyl ${ }^{60}$ and carboxyl ${ }^{72}$ groups attached to it are spatially isolated even at concentrations of $1 \mathrm{mmol} /$ g.) Under certain conditions this polymer behaves as a rigid matrix even when solvent swelled as was shown very recently by Regen and $\mathrm{Lee}^{73}$.

Chloromethylated two per cent crosslinked polystyrene $(0.5 \mathrm{mmol} \mathrm{Cl} / \mathrm{g})$ when treated with $N, N, N^{\prime}, N^{\prime}$-tetramethylethylenediamine released only 50 per cent of the theoretical amount of $\mathrm{Cl}^{-}$. Thus monofunctional binding

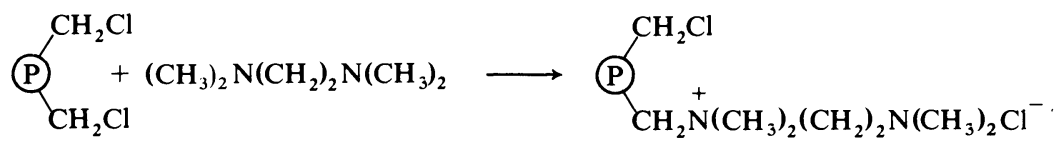

occurred as shown in equation 23. The amount of $\mathrm{Cl}^{-}$did not increase even when higher temperatures and long reaction times were employed. More $\mathrm{Cl}^{-}$was obtained, however, when either the chlorine concentration in the polymer was higher or the diamine chain was longer. The important factor contributing to rigidity in these reactions is probably the high charge which is formed on the polymer during reaction. 
THE USE OF POLYMERIC REAGENTS IN ORGANIC SYNTHESIS

Other polymers (e.g. popcorn and highly crosslinked macroporous polystyrenes) proved to be more rigid than non-charged two per cent crosslinked polymer (vide supra).

\section{NOVEL ASPECTS OF POLYMERIC REAGENTS}

Recent reports describe novel uses of polymers in chemical research. In one such use a racemate was resolved by an enzyme-like polymer ${ }^{74}$. Polymers with functional groups juxtaposed in an exact, predetermined steric relationship were prepared by polymerizing monomers around optically active templates XLV as shown in Scheme 8.

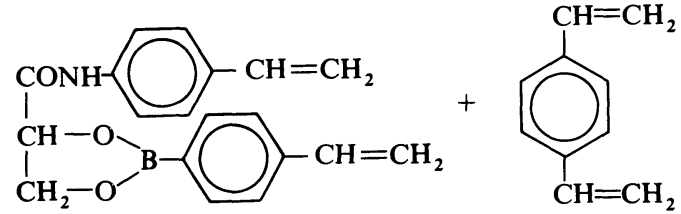

XLV

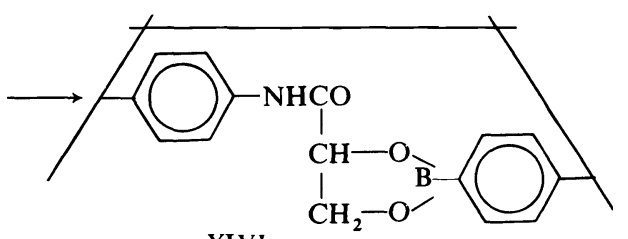

XLVI

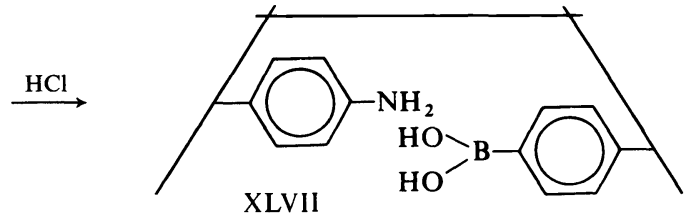

Scheme 8

If the polymer formed is completely rigid, then the voids remaining upon removal of the template, should accommodate better that isomer which was used as template than its enantiomer. This was indeed the case; polymer (XLVII), formed with D-glyceric acid as template, bound this acid better than its L-form. This approach constitutes resolution by asymmetric cavities rather than by asymmetric reagents. The ability of the polymer to resolve racemates is irreversibly lost upon swelling.

Another novel reaction utilizes the fact that two compounds, which

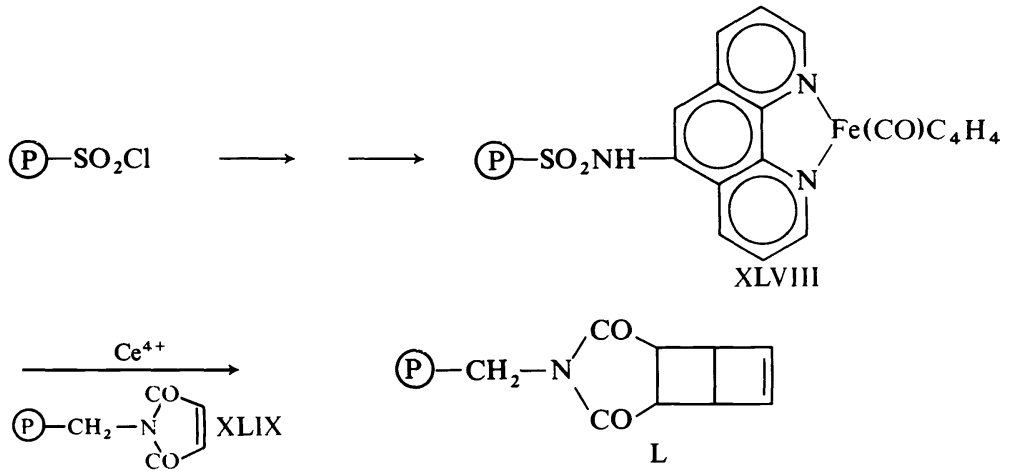




\section{A. PATCHORNIK AND M. A. KRAUS}

usually react with each other, are made mutually inert by attachment to two batches of insoluble polymer respectively ${ }^{64}$. Rebek et al. made use of two polymeric reagents in an elegant method to demonstrate the existence of reactive intermediates in reactions ${ }^{75}$. This is shown in equation 24 .

The cyclobutadiene precursor polymer (XLVIII) was treated with $\mathrm{Ce}^{4+}$ in the presence of the trapping polymer (XLIX). The formation of polymer (L) constitutes a proof that free cyclobutadiene is formed in this reaction.

\section{CONCLUDING REMARKS}

The advantages of using polymers as reagents and carriers in synthesis were illustrated. The insolubility of the polymeric reagent has been utilized in the following ways. When used as transfer agent, a large excess of polymeric reagent may be employed, often leading to very high yields and product purity. In some cases side products remain attached to the polymer facilitating purification of the desired product. In another application the insolubility of the polymeric reagent is utilized for many repetitions of a synthetic step which produces only a low yield of product. In another type of synthesis the insolubility of the polymer enables the use of a large excess of soluble reagent (easily removed after reaction, thus leading for example to selective reactions of multifunctional compounds. Carrier insolubility may also be employed to make two reactive species inaccessible to each other (by their binding to two different polymer batches). The advantage of immobilization of polymer-attached moieties may be used to separate reactive species from each other, thus enabling their selective intramolecular reaction, or reaction with a soluble reagent. At high concentration of attached species the polymer may cause their close mutual proximity and hence, under proper conditions, fast and selective intrapolymeric reactions. Special polar effects caused by the polymer backbone may change the normal course of reactions. Defined steric conditions in rigid polymers may be used for selective separations of mixtures.

In addition to these very real advantages, a few disadvantages of the use of polymeric reagents should be realized.

Attachment to-and sometimes detached from-the polymeric carrier are additional synthetic steps called for when using this approach. This obviously prolongs the synthesis and may sometimes decrease the yields. Accessibility of the polymer-attached species is sometimes unsatisfactory. Reactions occurring within polymeric matrices are often difficult to follow, as they are usually not amenable to common analytical methods such as u.v. and n.m.r. spectroscopy. Often, quantitative detachment from the polymer followed by conventional analysis is the only (or best) method of analysis. The polymeric carrier adds to the total volume used up by the reaction (less so if highly loaded) and if not regenerable many times-also to the cost.

It seems to us, however, that the merits outweigh the limitations of the method. Often this approach offers possibilities not attainable in other ways. In other instances high yields and pure products make the method attractive for laboratory use and even on a large scale. Finally, as this is still a relatively new field, probably not all possible advantages of the use of polymeric 
reagents have been explored yet. The demonstration of new, unique advantages of reactions with polymeric reagents over conventional reactions in solution is to be expected in the future.

\section{ACKNOWLEDGEMENT}

Financial support from the Camille and Henry Dreyfus Foundation which helped in the preparation of this review is gratefully acknowledged.

\section{REFERENCES}

1 R. Goldman, L. Godstein and E. Katchalski, in Biochemical Aspects of Reactions on Solid Supports, Ch. 1. G. R. Stark (ed.) Academic Press: New York (1971).

2 F. Helfferich, Ion Exchange, McGraw-Hill: New York (1962).

3 H. G. Cassidy and K. A. Kun, Oxidation-Reduction Polymers, Interscience: New York (1965).

4 J. M. Stuart and J. D. Yang, Solid Phase Synthesis, Freeman: San Francisco (1969).

5 P. Cuatrecasas and C. B. Anfinsen, Ann. Rev. Biochem. 40, 259 (1971).

6 C. M. Pittman Jr and G. O. Evans, Chem. Tech. 560 (1973).

7 C. G. Overberger and K. N. Sannes, Angew. Chem. Internat. Ed. 13, 99 (1974).

8 M. Fridkin, A. Patchornik and E. Katchalski, Israel J. Chem. 3, 69p (1965).

9 M. Fridkin, A. Patchornik an'd E. Katchalski, J. Amer. Chem. Soc. 88, 3164 (1966).

10 M. Fridkin, A. Patchornik and A. Katchalski, J. Amer. Chem. Soc. 90, 2953 (1968).

11 R. Kalir, M. Fridkin and A. Patchornik, Europ. J. Biochem. 42, 151 (1974).

12 M. Fridkin, unpublished results.

12 a G. T. Panse and D. A. Laufer, Tetrahedron Letters, 4181 (1970).

13 M. Fridkin, A. Patchornik and E. Katchalski, Biochemistry, 11, 466 (1972).

14 R. Kalir, A. Warshawsky and M. Fridkin, unpublished results.

15 Th. Wieland and Ch. Birr, Angew. Chem. Internat. Ed. 5, 310 (1966).

16 Th. Wieland and Ch. Birr, Chimia, 21, 581 (1967).

17 D. A. Laufer, T. M. Chapman, D. F. Marlborough, V. M. Vaidya and E. R. Blout, J. Amer. Chem. Soc. 90, 2692 (1968).

18 M. Akiyama, Y. Yanagisawa and M. Okawara, J. Polym. Sci. A-1, 7, 1905 (1969).

19 G. R. Marshall and I. E. Liener, J. Org. Chem. 36, 867 (1970).

20 M. Guarneri, R. Ferroni, P. Giori and C. A. Bennasi, Chemistry and Biology of Peptides, p 17. Ann Arbor Science Pub.: Ann Arbor, Mich. (1972).

21 M. B. Shambu and G. A. Digenis, Tetrahedron Letters, 1627 (1973).

22 T. L. Ang and J. Harwood, J. Macromol. Sci. Chem. A7, 1079 (1973).

23 J. Z. Zabicky, I. Oren and E. Katchalski, US Pat. No. 3700610.

24 M. L. Hallensleben, Angew. Makromol. Chem. 27, 223 (1972).

25 C. Yaroslawsky, A. Patchornik and E. Katchalski, Tetrahedron Letters, 3629 (1970).

26 C. Yaroslawsky and E. Katchalski, Tetrahedron Letters, 5173 (1972).

27 M. L. Hallensleben, Angew. Makromol. Chem. 31, 143 (1973).

28 A. Page Lecuger, J. L. Luche, H. B. Kagan. G. Colin and C. Mazieres, Bull. Chim. Soc. France, 1690 (1973).

29 F. Helfferich and D. B. Luten, J. Appl. Polym. Sci. 8, 2899 (1964).

30 T. Tagaki, Polym. Letters, 5, 1031 (1967).

31 K. Kondo, T. Fujita and K. Takemoto, Makromol. Chem. 174, 7 (1973).

32 M. Gorecki and A. Patchornik, Biochim. Biophys. Acta, 303 (1973).

33 F. Camps, J. Castells, J. Font and F. Vela, Tetrahedron Letters, 1715 (1971).

34 W. Heitz and R. Michels, Angew. Chem. 84, 296 (1972).

35 S. V. McKinley and J. W. Rakshys Jr, Chem. Commun. 134 (1972).

36 M. Schlosser and K. F. Christmann, Liebigs Ann. Chem. 708, 1 (1967).

37 W. Heitz and R. Michels, Liebigs Ann. Chem. 227 (1973).

38 M. Rubinstein and A. Patchornik, Tetrahedron Letters, 2881 (1972).

39 N. M. Weinshenker and C. M. Shen, Tetrahedron Letters, 3281, 3285 (1972).

40 Y. Wolman, S. Kivity and M. Frankel, Chem. Commun. 629 (1967). 


\section{A. PATCHORNIK AND M. A. KRAÜS}

${ }^{41}$ M. Fridkin. A. Patchornik and E. Katchalski, Peptides 1969, Proc. 10th Europ. Symp., p 166. North-Holland: Amsterdam.

42 R. E. Williams, J. Braun and D. R. Lauren, Polym. Preprints, 13(2), 823 (1972).

43 S. Tanimoto, J. Horikawa and K. Oda, Kogyo Kagaku Zasshi, 70, 1269 (1967).

44 D. Braun and E. Seelig, Angew. Chem. 74, 694 (1962).

45 M. L. Hallensleben, Angew. Makromol. Chem. 31, 147 (1973).

46 L. M. Dowling and G. R. Stark, Biochemistry, 8, 4728 (1969).

47 G. Greber and S. Merchant, Int. Symp. Macromol. Chem., Budapest, 1969, Kinetics and Mechanism of Polyreactions, Vol. V, p 131.

48 S. Kopolow, T. E. Hogen and J. Smid, Macromolecules, 4, 359 (1971).

49 J. A. Campbell, J. Pharm. Sci. 52, 76 (1963).

50 I. T. Harrison and S. Harrison, J. Amer. Chem. Soc. 89, 5723 (1967).

51 J. Y. Wong and C. C. Leznoff, Canad. J. Chem. 51, 2452 (1973).

52 C. C. Leznoff and J. Y. Wong, Canad. J. Chem. 51, 3756 (1973).

53 U. Zehavi and A. Patchornik, J. Amer. Chem. Soc. 95, 5673 (1973).

54 J. M. Frecht and C. Shuerch, J. Amer. Chem. Soc. 93, 492 (1971).

55 G. C. Pimentel and S. W. Charles, Pure Appl. Chem. 7, 111 (1963).

${ }_{56}$ M. Fridkin, A. Patchornik and E. Katchalski, J. Amer. Chem. Soc. 87, 4646 (1965).

${ }^{57}$ L. Yu. Sklyarov and I. V. Shashkova, Zh. Obsch. Khim. 39, 2778 (1969).

58 E. Flanigan and G. R. Marshall. Tetrahedron Letters, 2403 (1970).

59 J. I. Crowley and H. Rapoport, J. Amer. Chem. Soc. 92,6364 (1970).

60 A. Patchornik and M. A. Kraus, J. Amer. Chem. Soc. 92, 7587 (1970).

61 M. A. Kraus and A. Patchornik, Israel J. Chem. 9, 269 (1971).

${ }^{62}$ F. Camps, J. Castells, M. J. Ferrando and J. Font, Tetrahedron Letters, 1713 (1971).

${ }^{63}$ M. A. Kraus and A. Patchornik, J. Polym. Sci. (C), in press.

${ }^{64}$ M. A. Kraus and A. Patchornik, J. Amer. Chem. Soc. 93, 7325 (1971).

${ }^{65}$ R. H. Grubbs, C. Gibbons, L. C. Kroll, W. D. Bonds and C. H. Brubaker Jr, J. Amer. Chem. Soc. 95,2373 (1973).

66 J. P. Collman, L. S. Hegedus, M. P. Cooke, J. R. Norton, G. Dolcetti and D. N. Marquardt, J. Amer. Chem. Soc. 94, 1789 (1972).

67 W. W. C. Chan, Biochem. Biophys. Res. Commun. 41, 1198 (1970).

68 N. M. Green and E. J. Toms, Biochem. J. 133, 687 (1973).

69 J. I. Crowley, T. B. Harvey III and H. Rapoport, J. Macromol., Sci. Chem. A7, 1117 (1973).

70 J. P. Collman and C. A. Reed, J. Amer. Chem. Soc. 95, 2048 (1973).

71 W. Lunkenheimer and H. Zahn, Liebigs Ann. Chem. 740, 1 (1970).

72 R. L. Letsinger, M. J. Kornet, V. Mahadevan and D. M. Jerina, J. Amer. Chem. Soc. 86, 5163 (1964).

${ }^{73}$ S. L. Regen and D. P. Lee, J. Amer. Chem. Soc. 96, 294 (1974).

${ }_{75}$ G. Wulff, A. Sarhan and K. Zabrocki, Tetrahedron Letters, 4329 (1973).

75 J. Rebek, personal communication. 